\title{
TRABALHO UNIDOCENTE SOBRE O TEMA SAÚDE A PARTIR DAS TRÊS DIMENSÕES DO CONTEÚDO: UM ESTUDO DE CASO NOS ANOS INICIAIS DE UMA ESCOLA ESTADUAL DO SUL DO BRASIL
}

\author{
Rhenan Ferraz Jesus \\ Brasil \\ Rosalvo Luis Sawitzki \\ Universidade Federal de Santa Maria, Santa Maria, Rio Grande do Sul, Brasil
}

Instituto Federal de Educação, Ciência e Tecnologia Farroupilha, Alegrete, Rio Grande do Sul,

\begin{abstract}
Resumo
A temática 'saúde' origina muitas reflexões e discussões sobre o seu conceito e de sua importância no âmbito escolar. Com isso, almejou-se compreender o posicionamento de cinco professoras unidocentes dos Anos Iniciais de uma escola estadual em um município gaúcho sobre o tema Saúde. Constituiu-se uma investigação descritiva qualitativa, caracterizada como um estudo de caso, dividida em quatro etapas: 1) levantamento bibliográfico; 2) autorização Coordenadoria Regional de Educação (CRE) e consentimento da Direção da escola e professoras; 3) aplicação de questionário; e 4) técnica de organização de dados e análise descritiva. Os resultados encontrados sinalizam, em grande parte, que pouco se tem feito nas atividades unidocentes para desvincular a transmissão de informações, que permeiam a abordagem conceitual de saúde. Além de que cada professora acaba tratando o tema saúde da maneira que a bem entende. Assim sendo, conclui-se sugerindo que os(as) professores(as) devam pensar em formas de melhor organizar os conteúdos da sua área com mais clareza e detalhada, bem como que procedimentos didáticos utilizar (os quais possibilitem aprendizagens), nas diferentes dimensões, diferenciados daqueles tradicionalmente vistos desde a fase inicial na formação do alunado.
\end{abstract}

Palavras-chave: Saúde. Professor. Proposta Pedagógica. Unidocente.

\section{Introdução}

O presente estudo vem tematizar a Saúde no âmbito escolar, em especial nos Anos Iniciais do Ensino Fundamental da Educação Básica, a partir do trabalho pedagógico e do posicionamento de professores atuantes nesta fase da escolarização formal. Esta investigação emergiu a partir de uma inquietação acadêmica, a qual é resultante de um trabalho monográfico realizado no Curso de Especialização em Educação Física Escolar (EFE) pelo Programa de Pós-Graduação em Educação Física (PPGEF) do Curso de Educação Física e Desportos (CEFD) da Universidade Federal de Santa Maria (UFSM). 
Até o presente momento, sabe-se que o termo Saúde tem provocado muita reflexão e discussão sobre o seu conceito, bem como de sua importância no âmbito escolar. No entanto, o questionamento que se faz aqui é de como trabalhar este tema em escolas públicas nos Anos Iniciais do Ensino Fundamental, oriundo de uma necessidade reflexiva sobre como os professores vêm trabalhando a saúde enquanto temática no ambiente escolar, e um dos conteúdos da disciplina de Educação Física, bem como a articulação entre a educação para a saúde e a programação do conjunto dos conteúdos escolares para o primeiro ciclo da Educação Fundamental.

Os motivos que levaram à escolha desse tema são variados, destacando entre eles o entendimento de Florence e Araújo (2005):

[...] após vigência da nova Lei de Diretrizes e Bases da Educação Nacional (LDBEN) - Lei $\mathrm{N}^{\circ}$. 9.394/96, o apontamento da Educação Física como componente curricular obrigatório na Educação Básica, mas não sendo obrigatória a sua realização por um profissional devidamente habilitado em Licenciatura na Educação Física nas fases da educação infantil e anos iniciais (antiga séries inicias) - Ciclo I.

As escolas geralmente contam com apenas um professor para cada turma nos anos inicias, chamado de "unidocente" ou "polivalente", sendo que o estado do Rio Grande do Sul prevê gratificações nos vencimentos dos professores que exercem a unidocência (Lei Estadual $\mathrm{n}^{\mathbf{o}}$ 10.576/1995), incentivando este tipo de atuação. Assim sendo, como foco de atenção neste trabalho, foi eleito o profissional de educação que opera na escola e o qual é um dos principais responsáveis para trabalhar esta relevante temática (Saúde) nos Anos Iniciais: o professor unidocente, pois este é considerado o atuante nessa fase educacional.

Outro motivo se reflete na compreensão de Monteiro (2012), de que a saúde, os fatores que a influenciam e determinam podem ser entendidos de diversas formas, o que acaba acarretando distintas abordagens para o seu ensino em sala de aula, bem como resultados de uma investigação de Costa, Gomes e Zancul (2012), relatando que, em muitas situações, os professores não têm sido preparados para abordar essa temática na escola e, conforme Nahas (1997) e Guedes (1999), a saúde é um dos temas pouco explorados pelos docentes.

No caso particular deste estudo, esse ensejo prevaleceu após uma análise dos documentos norteadores da escola estadual investigada, pois, nesta instituição de ensino, os planos de estudos apontam que há um enfoque prescritivo e memorizador referente ao tema saúde, o qual tange, predominantemente, o aspecto biológico (JESUS, 2014). Isso foi um alavanque para compreender o que se perpassa nessa realidade escolar, visto que a partir da década de 1980 surgiram novas propostas para superar os modelos tradicionais de ensino.

Em vista disso, sabendo da existência de conteúdos relacionados à Saúde nos Anos Iniciais, entende-se que este trabalho pode sim ser desenvolvido a partir do posicionamento dos professores unidocentes nos Anos Iniciais, pois a LDBEN (Lei $n^{\circ}$. 9.394/96) não institui quais profissionais devem atuar nos anos inicias, dando às redes de ensino a liberdade de escolherem o posicionamento sobre o assunto. Para isso, defende-se neste trabalho, como uma estratégia didático-pedagógica, a opção de uma proposta viável de ensino para a saúde, visando englobar as três dimensões do conteúdo, a saber: conceitual, procedimental e atitudinal. 


\section{Saúde no âmbito escolar: função da escola e o tratamento transversal}

Hoje, segundo Bracht (2001), os Parâmetros Curriculares Nacionais, no que se refere ao ambiente escolar e em função de algumas mudanças inerentes à própria sociedade, consideram a saúde como um tema transversal. Essa perspectiva de transversalidade partiu do Ministério da Educação e do Desporto (BRASIL, 1998a), onde foi criado o referencial curricular nacional para a educação fundamental, no qual a Saúde é tida como um tema transversal a ser trabalhado e assumido com responsabilidade no projeto de toda a escola. Tão logo, a proposta do Ministério da Educação (MEC) esboça a saúde como uma das peças-chave para a articulação entre as diferentes atividades e disciplinas escolares, bem como entre esta e a sociedade.

Neste contexto, como afirma Ceccim (2006, p.48), é possível compreender que a inserção da temática saúde no currículo escolar, estabelece a seguinte relação, onde "[...] a própria aprendizagem escolar se relaciona com o desenvolvimento da saúde individual, uma vez que se constitui em espaço de aquisição de informação sobre si, sobre o mundo, sobre a convivência social e sobre as relações sociais".

Concomitantemente, isso tenciona reflexões sobre o ambiente escolar, uma vez considerado como um espaço ideal para disseminar informações sobre si e do que está em torno do sujeito, bem como das relações existentes ali. Nesse sentido, Almeida (2006, p. 3) entende que os temas transversais vêm ao encontro da função da atual escola, a qual é de "[...] contribuir para a formação dos alunos como cidadãos integrados e atuantes na sociedade em que vivem". Também, Leonello e L'Abbate (2006, p.150) acreditam que nesse ambiente "[...] o indivíduo, em determinadas etapas da vida, aprende atitudes que são articuladas às suas experiências vivenciadas no cotidiano". Da mesma maneira, Valença Neto et al. (2012) salientam que existe o reconhecimento do ambiente escolar como ideal para traçar discussões que levam a refletir a respeito da importância de se manter saudável, bem como à adoção de um estilo de vida também saudável.

Para Coll (1998), a escola vai contribuir, ainda, para o desenvolvimento do aluno, sendo a aprendizagem o resultado de uma construção. Com esse pensamento, percebe-se a educação como um potencial gerador de saúde, onde a escola é vista como um lugar seguro e saudável, facilitando a adoção de comportamentos mais saudáveis, encontrando-se numa posição ideal para promover e manter a saúde da comunidade educativa e da comunidade envolvente (SCHULLER et al., 2003). É nesse ambiente que, pela Iniciativa Global de Saúde nas Escolas, estabeleceu-se a meta de aumentar o número de instituições escolares que possam ser qualificadas como Escolas Promotoras de Saúde - EPS (PEREIRA; PENTEADO; MARCELO, 2002).

A EPS é aquela que se coloca a serviço da promoção da saúde e atua nas áreas de ambiente saudável, oferta de serviços de saúde e educação em saúde (SILVEIRA, 2000). Desse modo, segundo Iervolino (2000), as escolas aparecem como excelente cenário de caráter formal, em que é possível gerar autonomia, participação crítica e criatividade para a promoção da saúde, que deve, no âmbito escolar, partir de uma visão integral, multidisciplinar do ser humano, considerando as pessoas em seu contexto familiar, comunitário e social. Assim sendo, acredita-se que, nesse profícuo espaço, uma das formas de contribuir para o processo de transformação da sociedade sem abrir mão dos conteúdos convencionais, conforme Busquets et al. (2000), é por meio da inclusão dos Temas Transversais na estrutura curricular da escola.

Esses mesmos autores defendem que os temas transversais deveriam ser o centro das preocupações do currículo em razão de sua importância para as transformações sociais necessárias. 
Além disso, entendendo que os conteúdos escolares deixem de ser tratados como um fim, passando a ser vistos como um meio para a aprendizagem dos grandes problemas sociais. Nas palavras de Busquets et al. (2000), os temas transversais se destinam a superar alguns defeitos perversos aqueles dos quais a sociedade atual se conscientizou de que, junto com outros de grande validade, herdamos da cultura tradicional.

Neste contexto, é possível notar nos Parâmetros Curriculares Nacionais - PCNs (BRASIL, 1998a, p. 26) que:

[...] nas várias áreas do currículo escolar existem, implícita ou explicitamente, ensinamentos a respeito dos temas transversais, isto é, todas educam em relação às questões sociais por meio de suas concepções e dos valores que veiculam nos conteúdos, no que elegem como critério de avaliação, na metodologia de trabalho que adotam, nas situações didáticas que propõem aos alunos.

De tal modo que, “[...] somente a participação das diferentes áreas, cada qual enfocando conhecimentos específicos à sua competência, com efeito, pode garantir que os alunos construam uma visão ampla do que é saúde" (BRASIL, 1998a, p. 263), justificando-se, assim, a opção de caracterizar a saúde como um tema transversal do currículo escolar.

Como apontam os PCNs (BRASIL, 1998a; 1998b), a escola, sozinha, não levará os alunos a adquirirem saúde, podendo e devendo, entretanto, fornecer elementos que os capacitem para uma vida saudável. Além disso, Lomônaco (2004a) entende que o currículo da educação deve estar voltado para a formação de um professor que possa trabalhar com as questões referentes à saúde de forma adequada. Por isso, embora a instituição educacional não tenha a tarefa precípua de dar atendimento a problemas de saúde dos alunos, existe uma obrigação inerente à profissão de ensinar, no sentido de promover o bem-estar das crianças e criar melhores condições para a sua aprendizagem (ANDERSON; CRESWELL, 1976). Assim, inevitavelmente, compreende-se que "as concepções de saúde que permeiam o ambiente escolar, advindas dos conceitos elaborados pelos educadores e profissionais que trabalham na escola, são possibilidades de se entender as ações ali desenvolvidas, em relação à saúde”. (LOMÔNACO, 2004b, p. 63).

Em vista do que foi exposto, e a fim de permear além da questão do tema transversal Saúde nas escolas, especialmente desde os Anos Iniciais do Ensino Fundamental, acredita-se que há uma necessidade maior, a qual se encontra subjetiva, na tentativa de desvelar o entendimento desta temática enquanto objeto pedagógico, buscando entender o seu processo como um todo. Para tal, neste estudo, espera-se despertar conhecimentos além dos existentes, podendo tratá-los nas três dimensões dos conteúdos, abordando os diversos aspectos que estão compostos acerca da definição da temática, como uma proposta didático-pedagógica ao ensino da saúde no contexto escolar.

\section{Procedimentos Metodológicos}

Esta investigação é caracterizada como um estudo de caso (LÜDKE; ANDRÉ, 2004), em virtude do pouco que se tem produzido sobre o trabalho unidocente e a temática Saúde nos Anos Iniciais, além de se estar buscando não generalizar os sujeitos investigados para um campo de vasta extensão, pois, o que se pretende perquirir condiz com a realidade do professor de Educação Física não poder atuar, inicialmente, em nas escolas públicas brasileiras nessa etapa da escolarização. Surgindo, desse modo, investigar o que os professores unidocentes, atuantes nessa fase, 'pensam', 
'sabem' e 'fazem' para trabalhar/abordar a temática saúde em suas atividades pedagógicas. Também, considerada uma pesquisa descritiva qualitativa, constituída em quatro etapas. Primeiramente, foi realizado um levantamento bibliográfico desde consultas em sites de produção científica, como em revistas eletrônicas e periódicos, trabalhos monográficos, dissertações e teses, a livros publicados que tratassem sobre o eixo temático Saúde. Em um segundo momento, entrou-se em contato com a $10^{\text {a }}$ Coordenadoria Regional de Educação (CRE) do Estado do RS, solicitando autorização para, por conseguinte, viabilizar a realização deste estudo em uma escola estadual, a qual está vinculada a essa CRE (responsável pela escola).

Assim sendo, como procedimento metodológico deste estudo, entrou-se em contato com a equipe diretiva de uma escola estadual no município de Manoel Viana/RS, para que fosse realizada essa pesquisa. Logo, quando obtida a permissão para realizar este trabalho, estabeleceu-se contato com as professoras unidocentes ${ }^{51}$ para que as mesmas pudessem participar deste estudo de maneira voluntária, onde seria mantido o anonimato das professoras. Para que fosse possível a participação das educadoras, as mesmas assinaram um Termo de Consentimento Livre e Esclarecido (TCLE), respeitando os critérios éticos da pesquisa conforme os termos da Resolução 466/2012 do Conselho Nacional de Saúde. Ressalta-se que este trabalho foi aprovado pelo Comitê de Ética em Pesquisa da Universidade Federal de Santa Maria (protocolo CAAE de nº. 40396114.9.0000.5346).

Depois disso, após o aceite de participação das unidocentes, passou-se para a terceira fase do estudo: a aplicação de um questionário com questões abertas (GIL, 2008) - procurando identificar que concepções orientam as atividades pedagógicas sobre o tema Saúde na ótica dessas professoras nos Anos Iniciais. O período para a coleta dos dados fora compreendido na primeira quinzena do mês de dezembro de 2013. O questionário foi elaborado pelos pesquisadores com duas questões, sendo uma delas bem específica sobre o trabalho do tema Saúde, conforme dispostas no Quadro 1.

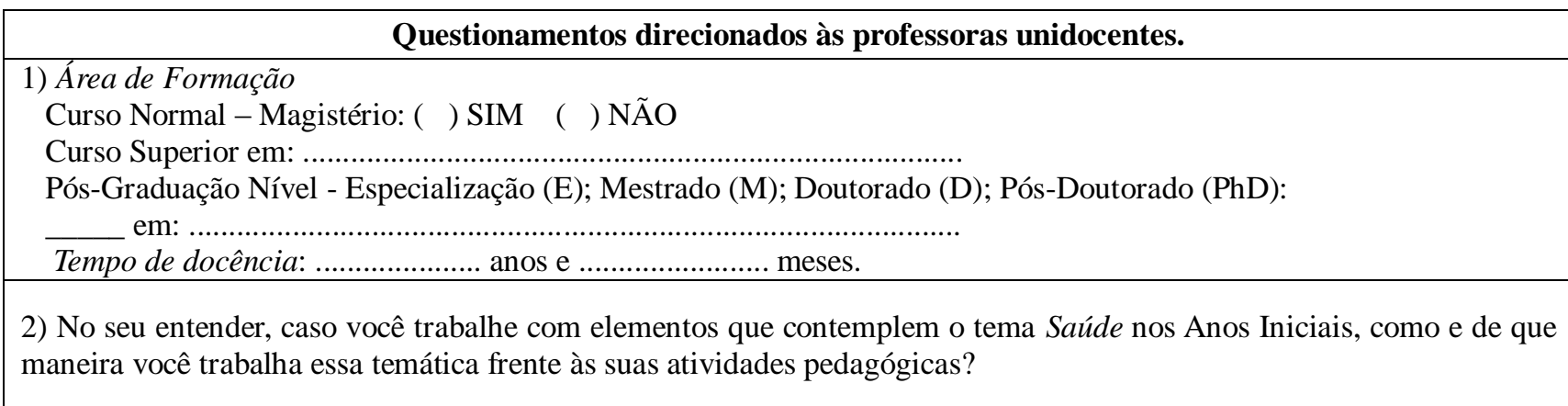

Quadro 1: Questões sobre a formação das professoras e o trabalho unidocente sobre o tema saúde.

A quarta etapa desta investigação se constituiu com uma técnica de organização de dados, além da interpretação das informações obtidas. De um modo breve, aderiu-se uma análise

\footnotetext{
${ }^{51}$ Nesta investigação, contou-se apenas com a participação de professoras unidocentes, as quais pertencem ao sexo feminino, e as quais são os únicos profissionais da educação que lecionam e estavam atuando nos Anos Iniciais desta escola estadual.
} 
estatística, utilizando as planilhas EXCEL 2010 para checagem automática e consistente das médias e desvio padrão das idades, bem como do tempo de atuação das unidocentes investigadas.

A partir das questões em estudo, e para melhor elucidar os resultados obtidos, subdividiu-se em duas categorias: a "Área de formação das Professoras unidocentes" e o "Trabalho unidocente sobre o tema saúde", esta última baseando-se nas três dimensões do conteúdo - a saber (ZABALA, 1998; COLL et al., 1998; DARIDO, 2004). Para a apresentação dos resultados, foram indicados pseudônimos (nomes de flores) para cada uma das professoras estudadas, com a finalidade de assegurar-lhes anonimato e sigilo das declarações. É importante ressaltar e compartilhar a existência de algumas limitações e dificuldades encontradas no desenvolvimento do presente estudo.

Entre uma das limitações e dificuldades, a recusa de uma das professoras em participar do proposto trabalho. Pelo breve relato desta professora unidocente, a decisão da rejeita se deu em virtude que ela estaria se desligando da escola investigada, segundo a mesma, por motivos pessoais. Assim sendo, entende-se que as informações que esta educadora poderia estar, de certa forma, corroborando expressivamente com os dados desta investigação.

\section{Resultados e Discussão}

Este tópico apresenta os resultados desta investigação subdivididos nas categorias elencadas a seguir, dialogados com a literatura e pesquisas realizadas na temática em estudo. Ressalta-se que este trabalho contou com a participação de cinco professoras unidocentes, de um total de seis, todas pertencentes a uma escola estadual localizada na cidade Manoel Viana, Rio Grande do Sul, o qual foi o representativo da amostra constituída na presente pesquisa.

\section{Área de formação das Professoras unidocentes}

No presente estudo foi possível evidenciar que todas as professoras têm curso superior em Pedagogia, sendo que três delas cursaram também o Magistério - Curso Normal. Além disso, três professoras possuem Pós-Graduação (titulação de Especialistas), duas delas em Psicopedagogia Institucional e outra em Educação Especial com ênfase em Inclusão. Em relação ao tempo de docência dessas profissionais, encontrou-se a média de 18,53 $( \pm 10,83)$ anos, apresentando tempo mínimo de quatro anos e máximo de trinta anos e seis meses. A faixa etária média encontrada foi de $48( \pm 3,08)$ anos, com mínima de 43 e máxima de 51 anos de idade.

Corroborando com esses dados, identificou-se uma pesquisa realizada por Santos e Bógus (2007), que buscava investigar o entendimento e a percepção que os professores têm quanto às temáticas da educação em saúde e da promoção da saúde na escola, estes atuantes no ensino fundamental de uma escola municipal de São Paulo. Por haver proximidades específicas e particularidades de um estudo de caso, houve semelhança em alguns dos procedimentos adotados, inclusive a primeira parte do questionário, que se referia à identificação dos respondentes (nome, idade, sexo, escolaridade) e informações profissionais.

Essas autoras trazem nesse estudo (SANTOS; BÓGUS, 2007), também, que todos os professores investigados $(\mathrm{n}=27)$ possuem curso superior, sendo que cinco deles apresentaram dois cursos superiores e um apresentou ter três cursos superiores. Ainda, apontaram que esses profissionais, que atuam há mais de dez anos, encontraram-se nas faixas etárias superiores a 44 anos. Comparando os dados, pode-se notar que em 2007, nessa escola de esfera municipal, os 
professores possuíam mais de uma graduação (Ensino Superior), e em 2013, nesta de esfera estadual, a maioria das professoras possuem titulação de especialistas. É possível perceber que os resultados cruzados das informações profissionais e formativas em ambas as pesquisas, ao longo de cinco anos, podem relevar a existência de alguns fatores que são pertinentes e que podem fazer sentido pela diferença apresentada nos achados.

Menciona-se aqui um desses possíveis fatores, os extensos avanços tecnológicos, os quais também são e podem ser influenciados pelas mudanças inerentes à própria sociedade, ainda mais quando se trata de uma época voltada à produção (trabalho) e divisão das classes sociais (poder). Conforme Ianni (1996), ao mesmo tempo em que o desenvolvimento tecnológico dispensa trabalhadores em alguns ramos da produção, cria outras atividades para as quais serão necessários outro tipo de força de trabalho, com outros conhecimentos e informações. Cria também a necessidade de trabalhadores com capacidades profissionais e conhecimentos específicos que deverão ser preparados para participarem do mercado de trabalho (IANNI, 1996). Ainda, para esse mesmo autor, sob as novas condições técnicas e organizacionais do processo produtivo há um rearranjo da força de trabalho que envolve capacidades profissionais mais qualificadas. Desta maneira, aumenta a demanda por trabalhadores especializados e diminui a procura por força de trabalho não qualificada ou semiqualificada (IANNI, 1996). É nesse diálogo que Carvalho (1997, p.105) deixa entender que esses avanços tecnológicos, inseridos no contexto da educação tecnológica, tem a tarefa de "preparar os trabalhadores qualificá-los e, assim, dar-lhes condições de participação neste mercado".

Para a Educação, nos últimos anos, o mercado de trabalho tem externado e ofertado inúmeras possibilidades para se qualificar em cursos formativos (sejam semipresenciais - encontros quinzenais, e/ou à distância - online, que boa parte processa de recursos tecnológicos) pra que o seu público-alvo possa se apoderar e permanecer trabalhando e estudando, simultaneamente, tendo um ensino mais 'flexível' e autônomo, não necessariamente que flexibilidade e autonomia sejam sinônimos de qualidade de ensino e aprendizagem. Tão logo, confrontados os dados, e mesmo apresentando duas realidades distintas, acredita-se que no presente momento esse anseio de ampliar a sua formação docente, ao mesmo tempo, vem atender a oferta de demandas da qualificação atual do mundo de trabalho. O qual denota estimar uma crescente procura de cursos e maiores probabilidades para se estar frequentando cursos de Pós-Graduação e/ou Aperfeiçoamento, que, em média, têm o tempo máximo de duração do curso em 18 meses, ao contrário de se buscar mais um curso de graduação, que detém um tempo maior de conclusão para o curso (média mínima em três anos), e que, também, pode vir a complementar uma formação inicial deficitária e estanque.

\section{Trabalho unidocente sobre o tema Saúde}

Buscando responder a questão de número dois no questionário utilizado, foram elencadas três formas de poder chegar a esta resposta, sobre "o que se deve saber" (dimensão conceitual), "o que se deve saber fazer" (dimensão procedimental) e "como deve ser" (dimensão atitudinal) trabalhada a temática saúde frente às atividades pedagógicas das professoras. Essa classificação, baseada em Coll et al. (1998), e que corresponde essas questões, tem a finalidade de alcançar os objetivos educacionais. $\mathrm{Na}$ verdade, quando se opta por uma definição de conteúdos tão ampla, não restrita aos conceitos, permite-se que esse currículo oculto possa se tornar manifesto e que se possa avaliar a sua pertinência como conteúdo de aprendizagem e ensino (ZABALA, 1998). 
Para "o que se deve saber", relevou-se os entendimentos conceituais adotados, bem como o uso de alguns instrumentos e materiais didáticos a serem trabalhados para que os alunos possam saber uma definição do que é Saúde.

"O tema saúde, é importantíssimo, é necessário que passassem para o aluno, conhecimentos em relação ao seu corpo e sua saúde, trabalhando a higiene, alimentação e o seu bem estar físico e mental [...]”." (BROMÉLIA).

"No primeiro trimestre são trabalhados temas como: hábitos de higiene; alimentação; cuidados com os dentes; dengue". (ROSA).

"O tema saúde é trabalhado relacionando o bem estar do aluno, trazendo-lhe informações em relação ao seu corpo e o meio em que ele vive". (TULIPA).

A partir desses relatos, pode-se afirmar que a Saúde continua sendo tratada na escola, desde os anos iniciais da escolarização formal, como meio de disseminação e transmissão de informações de como as pessoas adoecem, quais os principais ciclos de doenças, bem como os tipos de vacinas, desde normas e regras de higiene como eram considerados adequados dentro das instituições de ensino. Também, para o aluno, por intermédio dos conhecimentos relacionados ao seu corpo e à sua saúde, o meio em que ele vive, além do bem-estar físico e mental e hábitos saudáveis (higiene, alimentar). Para Zancha et al. (2013), transmitir informações a respeito do funcionamento do próprio corpo, descrever as características das doenças, bem como a divulgação de hábitos de higiene, alimentação e atividades físicas, não é o suficiente para que os alunos desenvolvam atitudes de vida saudável. Isso se reflete no pensamento de que "[...] o ensino da temática Saúde tem sido um desafio para a educação, no que tange à possibilidade de garantir uma aprendizagem efetiva $\mathrm{e}$ transformadora de atitudes e hábitos de vida." (ZANCHA et al., 2013, p. 205).

Segundo Coll (1997), na categoria de conhecimentos de natureza conceitual são englobados conceitos, fatos e princípios, sintetizando aquilo que o aluno, ao passar pelo processo de escolarização, deve "saber sobre". Para essa dimensão conceitual dos conteúdos, associa-se ao entendimento de Nahas (2006) que o ensino de "conceitos" ou informações básicas (através de aulas expositivas, discussões ou estudos de textos) requer uma sala de aula ou ambiente adequado onde os alunos possam se sentar com algum conforto e existam recursos pedagógicos para o professor.

Conforme Guedes (1999, p.11), “[...] a nível conceitual, com frequência o termo saúde tem sido caracterizado dentro de uma concepção vaga e difusa, o que incentiva interpretações arbitrárias e, por vezes, carente de uma visão didática-pedagógica mais consistente". Segundo esse mesmo autor, essa arbitrariedade tem oferecido uma multiplicidade de opiniões, programas e procedimentos relacionados à promoção da saúde no meio educacional. Em vista disso, os conceitos elaborados quanto ao que vem a ser saúde devem ser objeto de cuidadosa reflexão, para que se possa perceber e atuar de forma coerente no sentido de contribuir efetivamente na formação dos educandos (GUEDES, 1999).

Para "o que se deve saber fazer", empregou-se as atividades desenvolvidas pelo professor que envolvesse a participação dos alunos, suas vivências nas situações, que levassem na tomada de decisões e a realização de ações de forma ordenada, buscando atingir um fim. Com isso, foi possível notar em três relatos essas propriedades ditas e entendidas pela dimensão procedimental. 
Conforme a Professora Jasmim e a Professora Tulipa, elas percebem a participação efetiva dos alunos e professores em um projeto de saúde que a escola está engajada, e pela Professora Rosa, a participação dos alunos na confecção de cartazes e murais pela escola, como pela separação e classificação de objetos de limpeza e o seu uso, para que cada aluno possa estar, individualmente, vivenciando isso na prática de sua realidade.

"A escola participa de um projeto (PSE) onde trabalha a alimentação, saúde, com palestras nas quais todos os professores e alunos estão envolvidos”. (JASMIM).

"[...] O trabalho é feito com textos informativos; confecção de cartazes e murais; confecção de anúncios sobre materiais de higiene; confecção de álbuns de higiene; classificação de diferentes objetos de limpeza e sua utilização; caça-palavras; cruzadinhas; combinados da higiene; confecção de cartazes com as regras de higiene”. (ROSA).

"Trabalho com projetos, com leituras informativas, palestras, vídeos, cartazes". (TULIPA).

Pelos discursos, evidencia-se serem diversificados os procedimentos utilizados pelas unidocentes em suas atividades pedagógicas para se trabalhar a temática saúde nos Anos Iniciais na escola onde atuam. Tais procedimentos são entendidos como pouco satisfatórios, apesar de serem adequados, devido haver inúmeros exemplos/materiais existentes que podem ser trabalhados de maneira diferenciada dos métodos tradicionais, até então vistos. Sendo assim, cabe uma observação em relação à Professora Rosa, a qual denota em seu relato trabalhar a saúde (nas dimensões conceitual, procedimental e atitudinal) com um enfoque na "higiene". Segundo Darido (2003), a perspectiva higienista ainda é muito trabalhada pelos educadores que ainda resistem optar por uma educação mais tradicional. Esta tendência foi bastante influenciada pela medicina e pela eugenia e, de acordo com Darido e Rangel (2005), esta concepção possuía como preocupação principal os hábitos de higiene e saúde, valorizando tanto o desenvolvimento físico quanto o moral, a partir do exercício.

Para o trabalho na dimensão procedimental, associa-se Nahas (2006), quando ele sugere a apresentação de materiais de leituras, como livros, revistas, folhetos, etc., os quais devem estar à disposição dos alunos para consulta. Como defende Loureiro (1996a; 1996b), é essencial que os professores busquem alternativas pedagógicas e curriculares que venham a melhorar o seu ensino dentro da escola, além disso, que possam estimular o alunado, por meio da incorporação de atividades, em se apossar (fazer parte) de um estilo de vida saudável, que visem colaborar à promoção e à conservação de sua saúde.

Essa dimensão procedimental, segundo o que Freire e Mariz de Oliveira (2004, p.142), “[...] é composta por técnicas, habilidades ou procedimentos que são executados de acordo com uma determinada finalidade". Para esses autores, são os procedimentos que permitem nossa interação e ação no mundo. Sua aprendizagem exige a execução repetida, num processo de tentativa e erro. Mas, se a prática é algo essencial para a aprendizagem de uma habilidade, ela sozinha não basta. Nessa perspectiva, Coll (1998) enfatiza que a seleção dos procedimentos a serem aprendidos na escola deve estar pautada na identificação de sua relevância para potencializar o desenvolvimento global do aluno e para capacitá-lo a agir de forma construtiva na sociedade. 
Em relação "como deve ser", Zabala (1998) entende que é possível associar aos valores, atitudes, normas e posturas que influenciam dentro da comunidade escolar, que possuem relação à perspectiva educacional de responsabilidade e valorativa, o que para Coll (1997) são os elementos integrantes da dimensão atitudinal. Sendo assim, percebe-se que duas unidocentes procuram orientar os alunos sobre saúde, além de poder estimular e incentivá-los a adotarem posturas e hábitos saudáveis que agreguem sua vida, considerando sua realidade.

\begin{abstract}
"Orientando os alunos sobre prevenção de doenças e que eles tenham noções fundamentais sobre higiene e que saibam a importância e a necessidade de se ter uma boa higiene [...] ". (ROSA).

"Posso dizer que todo o dia é dia de trabalhar o tema Saúde na escola, pois no decorrer da aula vão surgindo oportunidades que são aproveitadas para orientar, estimular $e$ enriquecer os cuidados que devemos ter com a saúde. Incentivando sempre os alunos a adotarem posturas e hábitos que valorizem uma vida saudável, seja na escola, em casa ou aonde eles forem”. (MARGARIDA).
\end{abstract}

Pelo enunciado da Professora Rosa, a sua parece estar mais vinculada a uma noção de 'higienismo', como se fossem a única forma para se promover saúde no âmbito escolar. No relato da Professora Margarida há uma proximidade maior como o proposto, ficando mais evidente quando a mesma afirma orientar, estimular e incentivar os alunados a buscarem valorizar uma vida mais saudável.

Nessa visão atitudinal, é possível compreender a partir de Nahas $(2006$, p.160) que, “[...] como em qualquer processo educacional, o recurso principal está na figura do professor". Segundo esse mesmo autor, o conhecimento do assunto e a capacidade de promover um ambiente motivador e estimulante para a aprendizagem são fundamentais. Segundo Iervolino (2000), essas conquistas orientam o aluno para o reconhecimento e expressão de suas necessidades, possibilitando a oportunidade de refletir sobre seu papel histórico e colaborando para possíveis transformações por intermédio da consciência e mudança social. Conforme Zabala (1998), as atividades devem partir de situações significativas e funcionais, a fim de que o conteúdo possa ser aprendido, habilitando o aluno a utilizá-lo quando for conveniente ou necessário.

Em um geral, observa-se que as professoras trabalham a temática saúde, predominantemente, na dimensão conceitual dos conteúdos e de maneira transmissiva, buscando apresentar aos alunos conhecimentos e objetivos relacionados à sua atividade pedagógica, seja pela utilização de vídeos, como leituras informativas e o uso de outros recursos didático-pedagógicos. Ainda, apenas três delas apresentaram um entendimento sobre saúde que visa englobar a dimensão procedimental dos conteúdos, por meio da participação dos alunos em projetos e confecção de cartazes e murais pela escola; bem como duas professoras a um entendimento à dimensão do conteúdo atitudinal, procurando orientar, estimular e incentivá-los a adotarem posturas e hábitos saudáveis às suas vidas. Mesmo assim, pela proposta de trabalho docente encontrada, pode-se notar que apenas uma unidocente apresentou trabalhar as três dimensões do conteúdo, a saber - a conceitual, procedimental e atitudinal.

Segundo Neira (2006), a tipologia de conteúdos pode servir de instrumento para definir as diferentes posições sobre o papel que o ensino deve ter. Assim, ao buscar a formação integral dos alunos, a presença de diferentes tipos de conteúdos deve ser equilibrada. Essa classificação não 
deve ser interpretada de forma rígida e um mesmo conteúdo pode ser abordado numa perspectiva factual, conceitual, procedimental ou inclusive atitudinal ao mesmo tempo.

No entanto, nessa perspectiva, notou-se que a maioria das respostas faz referência à Saúde como sendo uma transmissão de conhecimentos, como se estes fossem o suficiente para que o indivíduo transforme sua postura na perspectiva da manutenção da saúde e estabeleça o princípio da qualidade de vida em suas atividades cotidianas. Gavidia (2009) vem acrescentar que a Educação em Saúde não se resume na apenas na transmissão de conhecimento, para, além disso, Fernandes, Rocha e Souza (2005) afirmam que a maior parte dos professores não consegue compreender a saúde como uma questão global, que não envolve demandas apenas relacionadas à higiene, alimentação e doenças.

Assim sendo, foi possível associar o posicionamento dessas unidocentes investigadas onde, além de compreender a existência de conteúdos relacionados à Saúde em seus discursos, a maioria delas trata essa temática de forma ampla e abrangente, já que algumas dessas docentes pareciam demonstrar uma dificuldade para externar o seu entendimento sobre saúde. Como, por exemplo, foi o relato da professora Margarida, a qual destacou a importância de se investir nos bons hábitos desde a infância, os cuidados com a saúde e o incentivo aos alunos para adotarem posturas e hábitos que valorizem uma vida saudável, desta forma, não sendo possível identificar uma definição mais objetiva e aproximada com a questão.

\section{Algumas Considerações}

Os resultados encontrados sinalizam, em grande parte, que pouco se tem feito nas atividades unidocentes para desvincular a transmissão de informações, que permeiam a abordagem conceitual de saúde, pois, o que se percebe é que cada professora acaba tratando o tema saúde da maneira que a bem entende para o ano do ensino fundamental que atuam. Mesmo assim, foi possível identificar a existência de conteúdos relacionados à Saúde nos Anos Iniciais no discurso das professoras investigadas. Em vista disso, recomenda-se que as professoras investigadas possam se desencilhar de um ensino estanque e tradicional calcado apenas no carreamento de informações, e para que isso seja possível, essa mudança não se pode iniciar diretamente na escola, nem nos alunos ou sociedade, muito menos nos conteúdos programáticos, mas sim na própria epistemologia da prática.

Por fim, acredita-se que o posicionamento das professoras, e da literatura estudada, como de muitos outros para trabalhar a temática saúde nas atividades pedagógicas (entre elas as três dimensões do conteúdo), vêm a contribuir para um melhor - e possível - entendimento da saúde como processo educativo. Desta forma, acredita-se que este trabalho vem cumprir o seu papel social, enquanto ferramenta e veículo disseminador do patrimônio cultural da humanidade, ao contribuir com investigações voltadas a temas pertinentes e de relevância na sociedade (saúde). Conclui-se, sugerindo que os(as) professores(as) devam pensar em formas de melhor organizar os conteúdos da sua área com mais clareza e detalhada, bem como que procedimentos didáticos utilizar (os quais possibilitem aprendizagens), nas diferentes dimensões, diferenciados daqueles tradicionalmente vistos desde a fase inicial na formação do alunado. 


\title{
SINGLE-TEACHER'S WORK ABOUT THE HEALTH ISSUE FROM THE CONTENT'S THREE DIMENSIONS: A CASE STUDY IN THE EARLY YEARS OF A STATE SCHOOL IN SOUTH BRAZIL.
}

\begin{abstract}
The health issue triggers many reflections and discussions about the its concept and importance in schools. Thus, this study has sought to understand the positioning on the Health theme of five single-teachers from the early years of a state school in a gaucho town. It has been constituted as a qualitative and descriptive research, featured as a case study, divided into four steps: 1) literature study; 2) the authorization by the Regional Coordination of Education (RCE) and the permission from the school Director and its teachers; 3) questionnaire application; and 4) data organization technique and descriptive analysis. The results indicate largely that little has been done in singleteachers activities to unlink the transmission of information, that permeates the conceptual approach to health. In addition, each teacher treats the health issue in the way that he pleases. Therefore, we have concluded by suggesting that the teachers should think of ways to better organize the contents of their field with more clarity and detail, as well as what pedagogical procedures (which allow learning) they must use in distinct dimensions, different from those traditionally used at an early stage of students formation.

Keywords: Health. Teacher. Pedagogical proposal. Primary teacher.

\section{EL TRABAJO DE LOS MAESTROS DE PRIMERO A CUARTO GRADO SOBRE EL TEMA DE LA SALUD DESDE LAS TRES DIMENSIONES DE CONTENIDO: UN ESTUDIO DE CASO EN LOS PRIMEROS AÑOS DE UNA ESCUELA PÚBLICA EN EL SUR DE BRASIL.}

\section{Resumen}

El temática Salud origina muchas reflexiones y discusiones sobre su concepto y su importancia en las escuelas. Por lo tanto, este estudio ansiaba comprender la posición cinco maestros de primero a cuarto grado de los primeros años de una escuela pública en un pueblo gaucho sobre el tema de la Salud. Formada una investigación cualitativa descriptiva, caracterizado como un estudio de caso, dividido en cuatro pasos: 1) estudio bibliográfico; 2) la autorización de la Coordinación Regional de Educación (CRE) y el consentimiento del Director de la escuela y los maestros; 3) la aplicación de lo cuestionario; y 4) la técnica de organización de los datos y el análisis descriptivo. Los resultados indican, en gran parte, de que poco se ha hecho en las actividades unidocentes para desvincular la transmisión de información que constituyen el enfoque conceptual de la salud. Además de que cada maestro ha manejado el tema de la Salud de la manera en que lo entienden. Así, ello se deduce sugerir que los maestros deben pensar en maneras de organizar mejor el contenido de su área com más clara y detallada, y que los procedimientos didácticos para ser utilizado (que permiten el aprendizaje), en las diferentes dimensiones, a diferencia de las que tradicionalmente se ve en la escuela.

Palavras-clave: Salud. Maestro. Propuesta pedagógica. Maestro unidocente. 


\section{Referências}

ALMEIDA, T. J. B. Abordagem dos Temas Transversais nas aulas de Ciências do Ensino Fundamental, no Distrito de Arembepe, município de Camaçari-BA. Candombá, v. 2, n. 1, p. 1-13, jan./jun. 2006.

ANDERSON, C. L.; CRESWELL, W. H. School health practice. 6th ed. St. Louis: C.V. Mosby, 1976.

BRACHT, V. Saber e fazer pedagógicos: acerca da legitimidade da Educação Física como componente curricular. In: CAPARRÓZ, Francisco E. (org.). Educação Física escolar: política, investigação e intervenção. Vitória: Proteoria, 2001, p.67-79.

BRASIL. Parâmetros Curriculares Nacionais: terceiro e quatro ciclos do ensino fundamental: temas transversais. Brasília: MEC/SEF, 1998a. 436p.

BRASIL. Parâmetros Curriculares Nacionais: primeiro e segundo ciclos do ensino fundamental: Tema Transversal Saúde. Brasília: MEC/SEF, 1998b.

BRASIL. Secretaria da Educação Fundamental. Parâmetros Curriculares Nacionais: introdução aos Parâmetros Curriculares Nacionais. Brasília: MEC/SEF, 1997.

BUSQUETS, M. D.; CAIZOS, M.; FERnÁNDEZ, T.; LEAL, A.; MORENO, M.; SASTRE, G. Temas transversais em Educação: bases para uma formação integral. 6.ed. São Paulo: Ática, 2000 .

CARVALHO, M. G. de. Tecnologia, Desenvolvimento Social e Educação Tecnológica. Revista Educação \& Tecnologia, n. 1, p. 98-106. jul. 1997.

CECCIM, R. B. Saúde e doença: reflexão para a educação da saúde. In: MEYER, D. E. E. Saúde e Sexualidade na escola. (pp. 37-50). Porto Alegre: Mediação, 2006.

COLL, C. (Org). Construtivismo na sala de aula. São Paulo: Ática, 1998.

COLL, C. Psicologia e currículo. São Paulo: Ática, 1997.

COSTA, S.; GOMES, P. H. M.; ZANCUL, M. S. Educação em Saúde na escola na concepção de professores de Ciências e de Biologia. Anais... VII Encontro Nacional de Pesquisa em Educação em Ciências, 2011. Florianópolis: ABRAPEC, 2012. Disponível em: <www.nutes.ufrj.br/abrapec/viiienpec/resumos/R0922-1.pdf $>$. Acesso em: 18 Set. 2013.

DARIDO, S. C.; RANGEL, I. C. A. (org). Educação Física na escola. Rio de Janeiro: Guanabara Koogan, 2005. 
DARIDO, S. C. "Educação Física Escolar: o conteúdo e suas dimensões". Pedagogia cidadã. Cadernos de Formação: Educação Física. São Paulo: Unesp, 2004. p. 59-70.

DARIDO, S. C. Educação Física na escola: questões e reflexões. Rio de Janeiro: Guanabara Koogan, 2003.

FERNANDES, M. H.; ROCHA, V. M.; SOUZA, D. B. A concepção sobre saúde do escolar entre professores do ensino fundamental $\left(1^{\mathrm{a}}\right.$ a $4^{\mathrm{a}}$ séries $)$. História, Ciências, Saúde, Manguinhos, v. 12, n. 2, p. 283-291, 2005.

FLORENCE, R. B. P.; ARAÚJO, P. F. de. A Educação Física frente a LDB 9394/96. Lecturas, Educación Física y Deportes, Buenos Aires, ano 10, n. 86, 2005. Disponível em: <http://www.efdeportes.com/efd86/ldb.htm>. Acesso em: 26 Out. 2013.

FREIRE, E. S.; MARIZ DE OLIVEIRA, J. G. Educação Física no Ensino Fundamental: identificando o conhecimento de natureza conceitual, procedimental e atitudinal. Motriz, Rio Claro, v.10, n.3, p.140-151, set./dez. 2004.

GAVIDIA, V. El profesorado ante la educación y promoción de la salud em la escuela. Didáctica de las Ciencias Experimentales y Sociales. v. 23, p. 171-180, 2009.

GIL, A. C. Métodos e técnicas de pesquisa social. 6. ed. São Paulo: Atlas, 2008.

GUEDES, D. P. Educação para a Saúde mediante programas de Educação Física escolar. Motriz, v. 5, n. 1, jun. 1999.

IANNI, O. A era do globalismo. Rio de Janeiro: Civilização Brasileira, 1996.

IERVOLINO, S. A. Escola promotora da saúde: um projeto de qualidade de vida. 2000. Dissertação (Mestrado) - Faculdade de Saúde Pública, Universidade de São Paulo, São Paulo. 2000.

JESUS, R. F. Entendimentos de professoras unidocentes sobre o tema saúde no contexto escolar: um estudo de caso nos Anos Iniciais de uma escola estadual. Monografia (Especialização em Educação Física Escolar). 2014. Universidade Federal de Santa Maria - UFSM. 2014. 77p.

LEONELLO, V. M.; L'ABBATE, S. Educação em Saúde na escola: uma abordagem o currículo e da percepção de alunos de graduação em Pedagogia. Interface - Comunicação, Saúde, Educação, v. 10, n. 19, p. 149-66. Jan/Jun, 2006.

LOMÔNACO, A. F. S. Concepções, ensino e práticas de saúde no cotidiano escolar: a educação para a saúde em escolas públicas de Uberlândia (MG). Dissertação (Mestrado em Educação). 2004. Universidade Federal de Uberlândia, Faculdade de Educação, 2004. 166p. 
LOUREIRO, C. F. A educação em saúde na formação do educador. Revista Brasileira de Saúde Escolar, 4, 3/4, 10-13. 1996a.

LOUREIRO, C. F. A problemática de saúde da criança no Brasil: desafios para uma prática educativa. Revista Brasileira de Saúde Escolar, v. 4, n. 1/2, p. 17-20. 1996 b.

LÜDKE, M.; ANDRÉ, M. E. D. A. Pesquisa em educação: abordagens qualitativas. 8. ed. São Paulo: EPU, 2004.

MONTEIRO, P. H. N. A saúde nos livros didáticos no Brasil: concepções e tendências nos anos iniciais do Ensino Fundamental. 2012. Tese (Doutorado em Educação) - Faculdade de Educação, Universidade de São Paulo, São Paulo, 2012. 210 f.

NAHAS, M. V. Atividade Física, saúde e qualidade de vida: conceitos e sugestões para um estilo de vida ativo. 4. ed. rev. e atual. Londrina: Midiograf, 2006.

NAHAS, M. Educação para a aptidão física e saúde: justificativa e sugestões para implementação nos programas de Educação Física. Revista Brasileira de Ciência e Movimento. v. 8, n. 03, 1997.

NEIRA, M. G. Educação física: desenvolvendo competências. 2. ed. São Paulo: Phorte, 2006.

PEREIRA, I. M. T. B.; PENTEADO, R. Z.; MARCELO, V. C. Promoção da Saúde e educação em saúde: uma Parceria saudável. Mundo da Saúde, v. 24, n. 1, p. 39-44. 2002.

SANTOS, K. F. dos; BÓGUS, C. M. A percepção de educadores sobre a escola promotora de saúde: um estudo de caso. Revista Brasileira de Crescimento e Desenvolvimento Humano, v. 17, n. 3, p. 123-133. 2007.

SCHUllER, T., PRESTON, J., HAMMOND, C., BRASSETT-GRUNDY, A.; BYNNER, J. The Benefits of Learning: The Impact of Education on Health, Family Life and Social Capital. London: Routledge Falmer, 2003.

SILVEIRA, G. T. Escola Promotora de Saúde: quem sabe faz a hora! 2000. Tese (Doutorado) Faculdade de Saúde Pública, Universidade de São Paulo, São Paulo. 2000.

VALENÇA NETO, P. F.; FERREIRA, A. S.; AMARAL, C. S.; PINHEIRO, D. C.; RODRIGUES, V. N.; SOUZA, M. C. Estágio Supervisionado I: educando para além do conceito de saúde. Lecturas, Educación Física y Deportes, Buenos Aires, ano 16, n. 164, 2012. Disponível em: <http://www.efdeportes.com/efd164/estagio-supervisionado-educando-conceito-saude.htm>.

Acesso em: 23 Set. 2013.

ZABALA, A. A prática educativa: como ensinar. Porto Alegre: Artmed, 1998. 
ZANCHA, D.; MARTINS, J.; SILVA, T. A. da; ABRAHÃO, T. A. Conhecimento dos professores de Educação Física Escolar sobre a abordagem Saúde Renovada e a temática Saúde. Conexões, Campinas, v. 11, n. 1, p. 204-217, jan./mar. 2013.

Recebido em: 10/03/2015

Revisado em: 16/04/2015

Aprovado em: 29/04/2015

Endereço para correspondência:

Rhenan Ferraz Jesus

rhenan.ferraz@hotmail.com

Instituto Federal Farroupilha, Campus Alegrete.

RST 377, Km 27

$2^{\circ}$ Distrito do Passo Novo

97555000 - Alegrete, RS - Brasil 